\title{
An Affine Regular Icosahedron Inscribed in an Affine Regular Octahedron in a GS-Quasigroup
}

\begin{abstract}
An Affine Regular Icosahedron Inscribed in an Affine Regular Octahedron in a GS-Quasigroup ABSTRACT

A golden section quasigroup or shortly a GS-quasigroup is an idempotent quasigroup which satisfies the identities $a(a b \cdot c) \cdot c=b, a \cdot(a \cdot b c) c=b$. The concept of a GSquasigroup was introduced by VOLENEC. A number of geometric concepts can be introduced in a general GSquasigroup by means of the binary quasigroup operation. In this paper, it is proved that for any affine regular octahedron there is an affine regular icosahedron which is inscribed in the given affine regular octahedron. This is proved by means of the identities and relations which are valid in a general GS-quasigrup. The geometrical presentation in the GS-quasigroup $\mathbb{C}\left(\frac{1}{2}(1+\sqrt{5})\right)$ suggests how a geometrical consequence may be derived from the statements proven in a purely algebraic manner.
\end{abstract}

Key words: GS-quasigroup, GS-trapezoid, affine regular icosahedron, affine regular octahedron

MSC2010: 20N05

\section{Introduction}

The concept of a GS-quasigroup was introduced by Volenec in [1].

A quasigroup $(Q, \cdot)$, which satisfies the identity of idempotency

$a a=a$

and the (mutually equivalent) identities

$a(a b \cdot c) \cdot c=b$,

$a \cdot(a \cdot b c) c=b$,

is called a golden section quasigroup or shortly a GSquasigroup.

\begin{abstract}
Afino pravilan ikozaedar upisan $u$ afino pravilan oktaedar u GS-kvazigrupi

\section{SAŽETAK}

Kvazigrupa zlatnog reza ili kraće GS-kvazigrupa idempotentna je kvazigrupa u kojoj vrijede identiteti $a(a b$. $c) \cdot c=b, a \cdot(a \cdot b c) c=b$. Pojam GS-kvazigrupe uveo je VoleneC. Razni geometrijski pojmovi mogu biti uvedeni u GS-kvazigrupi pomoću binarne operacije te kvazigrupe. Korištenjem relacija i identiteta u općoj GS-kvazigrupi u ovom je radu pokazano da se svakom afino pravilnom oktaedru može upisati afino pravilan ikozaedar. Geometrijski prikaz u kvazigrupi $\mathbb{C}\left(\frac{1}{2}(1+\sqrt{5})\right)$ pokazuje kako geometrijske tvrdnje mogu biti posljedica potpuno algebarskih razmatranja.
\end{abstract}

Ključne riječi: GS-kvasigrupa, GS-trapezoid, afino pravilan ikozaedar, afino pravilan oktaedar

It can be proved that the considered GS-quasigroup $(Q, \cdot)$ satisfies the identitites of mediality, elasticity, left and right distributivity, i.e., the identities

$a b \cdot c d=a c \cdot b d$,

$a \cdot b a=a b \cdot a$,

$a \cdot b c=a b \cdot a c$,

$a b \cdot c=a c \cdot b c$.

are valid. Some other identities, e.g.

$a(a b \cdot b)=b$,

$(b \cdot b a) a=b$,

are also valid in a general GS-quasigroup. 
Let us mention the best known example of a GSquasigroup. Let $\mathbb{C}$ be the set of points of the Euclidean plane. For any two different points $a, b$ we define $a b=c$ if the point $b$ divides the pair $a, c$ in the ratio of the golden section. In [1], it is proved that $(\mathbb{C}, \cdot)$ is a GS-quasigroup. This quasigroup is denoted by $\mathbb{C}\left(\frac{1}{2}(1+\sqrt{5})\right)$ because we have $c=\frac{1}{2}(1+\sqrt{5})$ if $a=0$ and $b=1$. As this quasigroup has a nice geometrical interpretation, we shall use this quasigroup for the purpose of illustrating the identities and relationships holding in a general GS-quasigroup.

From now on, let $(Q, \cdot)$ be any GS-quasigroup. The elements of the set $Q$ are said to be points.

Some geometric concepts, such as parallelograms, GStrapezoids, affine regular pentagons, an affine regular icosahedron and an affine regular octahedron, can be introduced by means of the given binary quasigroup operation (see [1], [2], [3], [4]).

The points $a, b, c, d$ are said to be the vertices of a parallelogram and we write $\operatorname{Par}(a, b, c, d)$ if the identity

$a \cdot b(c a \cdot a)=d$

holds. In [1], some properties of the quaternary relation Par on the set $Q$ are proved. It is proved that the structure $(Q, P a r)$ is a parallelogram space, i.e., that the following three properties hold:

(P1) For any three points $a, b, c$, there exists one and only one point $d$ such that there holds $\operatorname{Par}(a, b, c, d)$.

(P2) From $\operatorname{Par}(a, b, c, d)$ there follows $\operatorname{Par}(e, f, g, h)$, where $(e, f, g, h)$ is any cyclic permutation of $(a, b, c, d)$ or $(d, c, b, a)$.

(P3) From $\operatorname{Par}(a, b, c, d)$ and $\operatorname{Par}(c, d, e, f)$ there follows $\operatorname{Par}(a, b, f, e)$.

In [1], the following statement is proved.

Lemma 1 From Par (a,b,d,e) and Par(b,c,e,f) there follows $\operatorname{Par}(c, d, f, a)$.

We shall say that $b$ is the midpoint of the pair of points $a, c$ and write $M(a, b, c)$ if $\operatorname{Par}(a, b, c, b)$.

In [2], the concept of a GS-trapezoid is defined. The points $a, b, c, d$ successively are said to be the vertices of the golden section trapezoid and it is denoted by $G S T(a, b, c, d)$ if the identity

$a \cdot a b=d \cdot d c$

holds.

In [2], it is proved that any two of the five statements

$\operatorname{GST}(a, b, c, d), \operatorname{GST}(b, c, d, e), \operatorname{GST}(c, d, e, a)$,

$G S T(d, e, a, b), G S T(e, a, b, c)$ imply the remaining statement.

In [3], the concept of an affine regular pentagon is defined. The points $a, b, c, d, e$ successively are said to be the vertices of the affine regular pentagon and it is denoted by $A R P(a, b, c, d, e)$ if any two (and then all five) of the five statements (9) are valid.

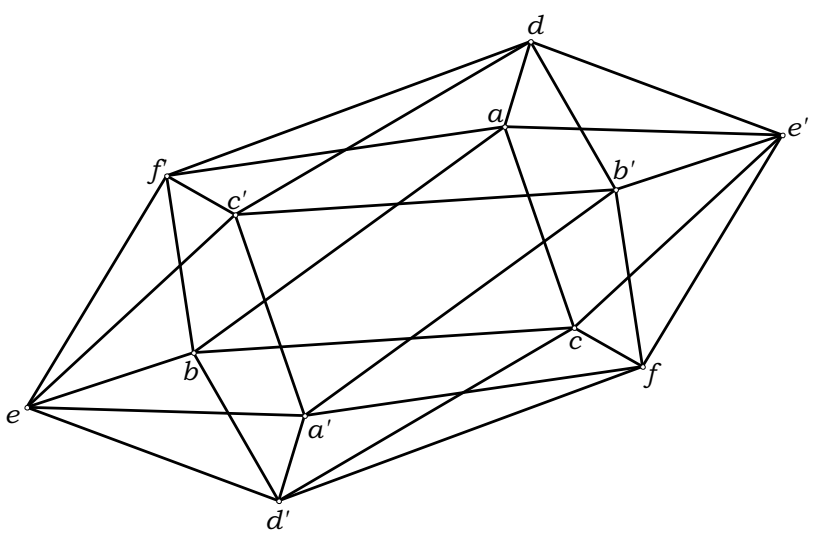

Figure 1: Affine regular icosahedron in $\mathbb{C}\left(\frac{1}{2}(1+\sqrt{5})\right)$

In [4], the concepts of an affine regular icosahedron and an affine regular octahedron in a general GS-quasigroup are introduced.

We shall say that the points $a, b, c, d, e, f, a^{\prime}, b^{\prime}, c^{\prime}, d^{\prime}, e^{\prime}, f^{\prime}$ are the vertices of an affine regular icosahedron (Figure 1) and write $\operatorname{ARI}\left(a, b, c, d, e, f, a^{\prime}, b^{\prime}, c^{\prime}, d^{\prime}, e^{\prime}, f^{\prime}\right)$ if the following twelve statements are valid

$A R P\left(b, c, f, a^{\prime}, e\right), \quad A R P\left(c, a, d, b^{\prime}, f\right)$,

$A R P\left(a, b, e, c^{\prime}, d\right), \quad A R P\left(b^{\prime}, c^{\prime}, f^{\prime}, a, e^{\prime}\right)$,

$\operatorname{ARP}\left(c^{\prime}, a^{\prime}, d^{\prime}, b, f^{\prime}\right), \quad \operatorname{ARP}\left(a^{\prime}, b^{\prime}, e^{\prime}, c, d^{\prime}\right)$,

$\operatorname{ARP}\left(b, c, e^{\prime}, d, f^{\prime}\right), \quad \operatorname{ARP}\left(c, a, f^{\prime}, e, d^{\prime}\right)$,

$\operatorname{ARP}\left(a, b, d^{\prime}, f, e^{\prime}\right), \quad \operatorname{ARP}\left(b^{\prime}, c^{\prime}, e, d^{\prime}, f\right)$,

$A R P\left(c^{\prime}, a^{\prime}, f, e^{\prime}, d\right), \quad A R P\left(a^{\prime}, b^{\prime}, d, f^{\prime}, e\right)$.

The points $a, b, c, a^{\prime}, b^{\prime}, c^{\prime}$ are the vertices of an affine regular octahedron with the center $o$ if the statements $M\left(a, o, a^{\prime}\right), M\left(b, o, b^{\prime}\right), M\left(c, o, c^{\prime}\right)$ are valid (Figure 2).

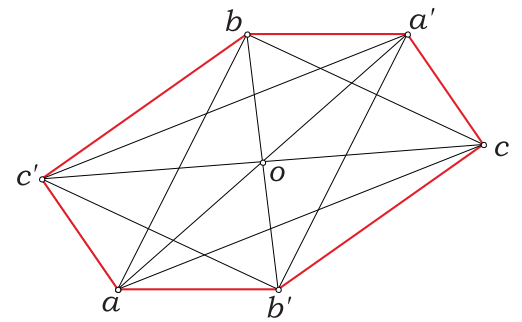

Figure 2: Affine regular octahedron in $\mathbb{C}\left(\frac{1}{2}(1+\sqrt{5})\right)$

The vertices of an affine regular octahedron are the vertices of three parallelograms. We have the statement. 
Lemma 2 From $M\left(c, o, c^{\prime}\right)$ and $M\left(b, o, b^{\prime}\right)$ there follows $\operatorname{Par}\left(b^{\prime}, c^{\prime}, b, c\right)$.

Proof. The statements $M\left(c, o, c^{\prime}\right)$ and $M\left(b, o, b^{\prime}\right)$ are equivalent to $\operatorname{Par}\left(c, o, c^{\prime}, o\right)$ and $\operatorname{Par}\left(b, o, b^{\prime}, o\right)$, from where, according to (P2), we get $\operatorname{Par}\left(o, b^{\prime}, o, b\right)$, whence by Lemma 1 we obtain $\operatorname{Par}\left(b^{\prime}, c^{\prime}, b, c\right)$.

In [4], it is proved that for any regular octahedron there is a regular icosahedron which is circumscribed to the given affine regular octahedron. Now, we shall prove that for any affine regular octahedron there is a regular icosahedron which is inscribed in the given affine regular octahedron. So, we have the following statement.

Theorem 1 If $a, b, c, a^{\prime}, b^{\prime}, c^{\prime}$ are the vertices of an affine regular octahedron, then $\operatorname{ARI}\left(a_{b}, b_{c}, c_{a}, a_{b^{\prime}}^{\prime}, b_{c^{\prime}}^{\prime}, c_{a^{\prime}}^{\prime}, a_{b^{\prime}}, b_{c}^{\prime}, c_{a^{\prime}}, a_{b}^{\prime}, b_{c^{\prime}}, c_{a}^{\prime}\right)$, where $a_{b}=a b \cdot b, b_{c}=b c \cdot c, \ldots, c_{a^{\prime}}^{\prime}=c^{\prime} a^{\prime} \cdot a^{\prime}$, (Figure 3).

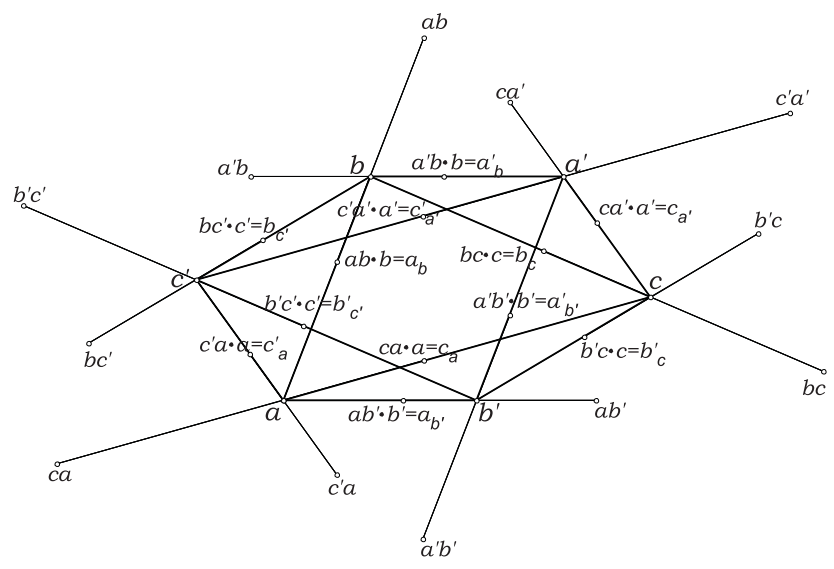

Figure 3.

Proof. It is enough to prove the statement $\operatorname{ARP}\left(a_{b}, c_{a}, a_{b^{\prime}}, b_{c^{\prime}}^{\prime}, b_{c^{\prime}}\right)$. According to (9), it is sufficient to prove that the statements $G S T\left(a_{b}, c_{a}, a_{b^{\prime}}, b_{c^{\prime}}^{\prime}\right)$ and $G S T\left(a_{b^{\prime}}, c_{a}, a_{b}, b_{c^{\prime}}\right)$ are valid. In fact, it is enough to prove only the first one because the second statement follows from the first one by substitution $b \leftrightarrow b^{\prime}$. According to the definition of a GS-trapezoid, because of (8), for the proof of the first statement we have to prove

$a_{b} \cdot a_{b} c_{a}=b_{c^{\prime}}^{\prime} \cdot b_{c^{\prime}}^{\prime} a_{b^{\prime}} \cdot$

We obtain

$$
\begin{aligned}
a_{b} \cdot a_{b} c_{a} & =(a b \cdot b) \cdot(a b \cdot b)(c a \cdot a) \\
& \stackrel{(3)}{=}(a b)(a b \cdot b) \cdot b(c a \cdot a) \\
& \stackrel{(5)}{=}(a \cdot a b) b \cdot b(c a \cdot a) \stackrel{\left(6^{\prime}\right)}{=} a \cdot b(c a \cdot a),
\end{aligned}
$$

from where, owing to (7), we get that the point $a_{b}$. $a_{b} c_{a}$ is the fourth vertex of the parallelogram with the vertices $a, b, c$, i.e., $\operatorname{Par}\left(a, b, c, a_{b} \cdot a_{b} c_{a}\right)$. We can get $\operatorname{Par}\left(b^{\prime}, c^{\prime}, a, b_{c^{\prime}}^{\prime} \cdot b_{c^{\prime}}^{\prime} a_{b^{\prime}}\right)$ in the same way. It is necessary to prove that the fourth vertices of these two parallelograms are coincident, i.e., the statement $\operatorname{Par}(a, b, c, x)$ implies the statement $\operatorname{Par}\left(b^{\prime}, c^{\prime}, a, x\right)$. However, because the points $b^{\prime}, c^{\prime}, b, c$ are the vertices of the octahedron, according to Lemma 2, $\operatorname{Par}\left(b^{\prime}, c^{\prime}, b, c\right)$ holds, which, together with $\operatorname{Par}(b, c, x, a)$ and by P3, gives $\operatorname{Par}\left(b^{\prime}, c^{\prime}, a, x\right)$.

In this case, we shall say that an affine regular icosahedron is inscribed in the given affine regular octahedron (Figure 4).

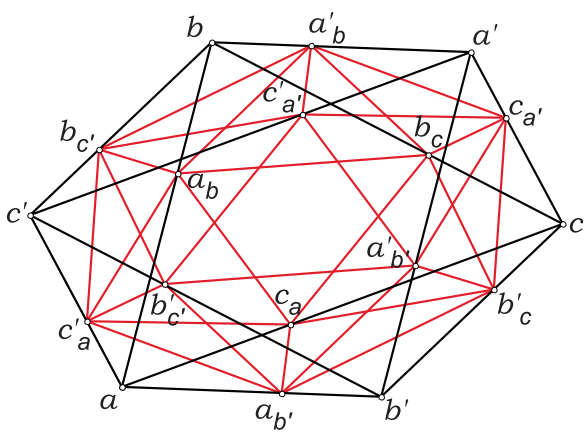

Figure 4.

\section{References}

[1] V. Volenec, GS-quasigroups, Čas. pĕst. mat. 115 (1990), 307-318.

[2] V. Volenec, Z. Kolar-Begović, $G S$-trapezoids in GS-quasigroups, Math. Commun. 7 (2002), 143158.

[3] V. Volenec, Z. Kolar-Begović, Affine regular pentagons in $G S$-quasigroups, Quasigroups Related Systems 12 (2004), 103-112.

[4] V. Volenec, Z. Kolar-Begović, R. KolarŠUPER, Affine regular icosahedron circumscribed around the affine regular octahedron in GSquasigroup, Comment. Math. Univ. Carolin. 53 (2012), 501-507.

\section{Zdenka Kolar-Begović} orcid.org/0000-0001-8710-8628 e-mail: zkolar@mathos.hr

Department of Mathematics, University of Osijek Gajev trg 6, HR-31000 Osijek, Croatia 